\title{
A LITERATURA ROMÂNTICA DE GOETHE ATRAVÉS DA OBRA OS SOFRIMENTOS DO JOVEM WERTHER
}

\section{LA LITERATURA ROMÁNTICA DE GOETHE POR MEDIO DE LA OBRA LOS SUFRIMIENTOS DEL JOVEN WERTHER}

Mayla Louise Greboge Montoia ${ }^{1}$

Resumo: Este artigo é resultado de uma pesquisa realizada na disciplina de Teoria da História III, na Universidade Federal do Paraná (UFPR) e tem como finalidade relacionar os debates da disciplina com a literatura produzida no período de estudo, séculos XVIII e XIX. A obra escolhida foi "Os sofrimentos do Jovem Werther" de 1774, do escritor alemão Johann Wolfgang von Goethe. Com base em uma categorização proposta pelo historiador Michel Löwy, Goethe pode ser considerado um verdadeiro romântico, que sente saudade do passado, é pessimista quanto ao futuro, avesso à racionalidade e que vive um constante conflito entre indivíduo e sociedade. Ao longo do artigo, busca-se demonstrar de que forma e por que esta obra permite chegar a tais conclusões.

Palavras-chave: Literatura; História; Romantismo; Goethe.

Resumen: El siguiente artículo es resultado de una investigación realizada en la clase de Teoría de la Historia III, en la Universidade Federal do Paraná (UFPR), y tiene como finalidad relacionar los debates de la clase con la literatura producida en el periodo del estudio, los siglos XVIII y XIX. La obra escogida fue "Los sufrimientos del joven Werther" de 1774, del gran escritor alemán Johann Wolfgang von Goethe. Partiendo de la categorización propuesta por el historiador Michel Löwy, Goethe puede ser considerado un verdadero romántico, que extraña al pasado, es pesimista en relación al futuro, contrario a la racionalidad, y que vive en constante conflicto entre el individuo y la

\footnotetext{
${ }^{1}$ Mestranda e graduada em História pela Universidade Federal do Paraná.
} 
sociedad. A lo largo del artículo, se busca demostrar de que manera y por qué esta obra nos permite llegar a tales conclusiones.

Palabras-clave: Literatura; Historia; Romanticismo; Goethe.

\section{Introdução}

Em 28 de agosto de 1749, na cidade de Frankfurt, Alemanha, nasceu um dos maiores nomes da literatura alemã e do gênero romântico: Johann Wolfgang von Goethe. Oriundo de uma família de grande poder econômico, tanto Goethe quanto sua irmã tiveram acesso a uma educação de qualidade, com conhecimento de variadas línguas, das artes e da literatura. Pela influência de seu pai, que era jurista, Goethe iniciou seus estudos em Direito na faculdade de Leipzig, concluindo seu licenciamento em 1771 na cidade de Estrasburgo, onde conheceu Johann Gottfried Herder (1744-1803). Herder, filósofo e escritor alemão, foi uma grande influência em seu pensamento, especialmente nas orientações literárias, incluindo em seu repertório clássicos como Homero (928 a.C.-898 a.C), Ossian (1736-1796), Shakespeare (1564-1616) e também a cultura popular alemã. No ano seguinte, Goethe mudou-se para a cidade de Wetzlar onde, num baile, conheceu Charlotte Buff, sua grande paixão e inspiração, porém já comprometida com Johann Christian Kestner. O desenlace da relação fez com que Goethe saísse de Wetzlar no mesmo ano, publicando em 1774 uma de suas obras mais famosas, escrita em apenas quatro semanas: Os sofrimentos do Jovem Werther.

Sua produção, de acordo com o filósofo Marco Aurélio Werle (2018), apresenta uma nova proposta estética para o contexto. Nesta obra, ao se aproximar do leitor pelo formato epistolar e sentimental, 
Werther acaba por refletir de maneira real na vida de milhares de leitores, que se identificaram de tal forma com o personagem que caminharam para um mesmo destino - a morte. Este é um elemento bastante significativo da obra, como destaca o historiador Michel Löwy, uma vez que, "o artista romântico trava sua batalha contra a modernidade também no nível da forma" (LÖWY; SAYRE, 2015: 50). Para além dessa questão, Goethe é parte de um importante movimento de afirmação da cultura alemã que visava a uma nova sociedade, como veremos adiante.

Durante o século XVIII o conceito zivilisation, de origem iluminista e francesa, se disseminava cada vez com mais força entre as cortes europeias, sendo incorporado inclusive por Frederico II e pela aristocracia alemã, a qual a burguesia — da qual Goethe era parte — se organizava como forma de oposição. Goethe e toda uma juventude a ele contemporânea tornaram-se grandes críticos da sociedade especialmente através dos círculos universitários, do desenvolvimento intelectual e do movimento literário cultural Sturm und Drang ${ }^{2}$. Este movimento, segundo Löwy, pode ser considerado como um pré-romantismo, bastante característico da segunda metade do século XVIII, época também considerada por alguns autores como "Idade da Sensibilidade" (LÖWY; SAYRE, 2015: 69).

O ideal de civilidade associado à ideia de progresso foi comprado por Frederico II, embora o retrato da sociedade alemã fosse de pura

\footnotetext{
${ }^{2} \mathrm{O}$ termo que pode ser traduzido como "tempestade e ímpeto" refere-se a um movimento cultural bastante forte na literatura alemã na segunda metade do século XVIII, que valorizava as emoções, se contrapondo, desta forma, ao pensamento racional Iluminista.
} 
decadência. Desde o século anterior, a Alemanha sofria com a Guerra dos Trinta Anos e graves problemas econômicos e sociais. Entretanto, aderir à ideia de homem civilizado se justificava, pois este seria fruto de uma transformação social operada na modernidade, onde a polidez e a valorização dos gestos individuais de maneira racional tornavam-se cada vez mais fortes. Em substituição a esse conjunto de valores, que enfatizava um modelo de comportamento pautado por regras e no qual impulsos e paixões deveriam ser controlados, surgia um contraconceito - nas palavras de Norbert Elias - inerente ao povo alemão, denominado Kultur. A ênfase no individual, a valorização da autenticidade, a busca por profundidade e interiorização, o isolamento e o sentimentalismo eram alguns dos novos valores defendidos pelo Sturm und Drang. Através da literatura, a exemplo de Goethe, se fazia oposição à aristocracia, à Corte e toda importação cultural francesa. Portanto, mesmo sendo uma ficção, Os Sofrimentos do Jovem Werther pode ser compreendido como "uma representação figurada da experiência de uma geração" (SILVA, 2012: 12), o que nos permite analisá-lo para além de um romance de grandes paixões, isto é, como um meio de compreensão histórica através da literatura.

\section{Definição de romantismo}

A análise que segue é baseada na definição e tipologias desenvolvidas pelo historiador Michel Löwy acerca do romantismo e, para este fim, segue uma breve definição do que o autor entende por isso. Primeiramente, ele desacredita que um movimento, tão heterogêneo e duradouro como o romantismo possua apenas um 
elemento unificador. Sua análise do romantismo, portanto, considera aspectos políticos, econômicos e sociais de diferentes lugares ao longo do tempo — não privilegiando um elemento ou outro como realizam muitos autores. Contudo, segundo a ótica de Löwy podemos compreendê-lo de maneira geral como uma reação ao capitalismo e à sociedade burguesa que se afirmava entre os séculos XVIII e XIX, de diferentes formas.

Em vista disso, Löwy elabora seis tipologias de romantismo que serão comentadas brevemente. A primeira dela é o romantismo restitucionalista, caracterizado por uma "nostalgia de um estado pré-capitalista" (LÖWY; SAYRE: 87) e um desejo de reconstituição desse passado - muitas vezes associado a uma sociedade agrária tradicional ou mesmo à Idade Média. Já o romantismo conservador também sente saudade de um outro tempo e, embora aprecie o passado que existia antes da modernidade, não deseja restituí-lo. Este romantismo característico do fim do século XVIII e primeira metade do XIX acredita que o presente é um resultado natural das ações passadas, aceitando muitos elementos da sociedade burguesa. O romantismo fascista, além de possuir uma face política clara, é anticapitalista, com traços de antissemitismo, crítico à racionalidade iluminista que é exacerbada a ponto de glorificar o irracional que leva à justificação da violência e possui uma relação paradoxal com o indivíduo que ora é aniquilado (pelo Estado), ora é colocado em destaque (a exemplo do líder). Já o romantismo resignado é característico do fim do século XIX, quando o capitalismo já possui contornos irreversíveis. Resta ao indivíduo lamentar pelo passado perdido, mas também se resignar e 
criticar o presente. O romantismo reformador, ao contrário do resignado, acredita na possibilidade de retomar alguns valores do passado através de reformas. Por fim, a última categoria é o romantismo revolucionário e/ou utópico, este ao invés de buscar paliativos ou se resignar, aspira ao fim do capitalismo ou à instauração de um modo de vida igualitário que recuperaria alguns aspectos desse passado. Esse tipo de romantismo, para Löwy, possui muitos matizes que refletem as diferentes maneiras de causar essa ruptura, o que não convém mencionar aqui devido à extensão da análise do autor.

Dentre todas essas tipologias, Goethe parece se encaixar mais na do "romantismo restitucionista" no qual, segundo Löwy, está a maior parte dos escritores românticos, especialmente no período em que Goethe escreve e, com muita força na Alemanha. Este, como se verificará através de sua obra, é saudosista do passado vivido e pessimista quanto ao futuro, sendo possível identificar em sua obra um ardente "desejo de restituição, isto é, restauração ou recriação desse passado" (LÖWY; SAYRE, 2017: 87).

\section{A obra}

O romance epistolar intitulado Os sofrimentos do Jovem Werther (1774) é uma coletânea de cartas escritas por Werther, o personagem principal, endereçadas a seu melhor amigo, Guilherme. Narradas em primeira pessoa, as cartas de Werther apresentam pensamentos, aspirações, dúvidas, encantos e desencantos com a vida. Werther inicia sua carta relatando ao amigo suas primeiras impressões acerca do novo povoado no qual se instalou, Wahlheim. Sua nova vivenda aparece 
descrita como uma cidade interiorana cercada de natureza e pessoas simples que vivem muitas vezes no campo. De acordo com Marcelo Backes (2017), a descrição de Werther sobre Wahlheim tem muito a ver com a cidade alemã que o Goethe viveu, Wetzlar. Em uma nota, Backes relembra que, quando Goethe escreveu, geograficamente a Alemanha estava dividida em centenas de principados. Logo, a referência do personagem sobre a presença de um Bailio (representante de uma cidade pequena) na localidade, justifica uma aproximação da obra com as cidades da Alemanha no século XVIII (2017: 23).

Nesta primeira parte do livro, o personagem descreve sua chegada ao povoado, suas primeiras experiências, contatos estabelecidos com a população local, o encontro com Carlota (sua grande paixão), com o pretendente dela, Alberto, e comenta sua decisão de partir para a cidade. Segundo Backes (2017), através de fontes sobre a vida do próprio Goethe, é possível considerar que esta primeira parte do livro seja inspirada em sua experiência pessoal com Charlotte Buff e Johann Christian Kestner, quando esteve em Wetzlar. Assim como Werther, em vida, Goethe possuía uma grande amizade com o casal embora fosse apaixonado por Charlotte.

A fuga de Werther para a cidade, seu retorno a Wahlheim e sua desenfreada paixão por Carlota (culminando em suicídio), são elementos presentes na segunda parte do livro. Embora não mais inspirada na vida pessoal de Goethe, a segunda parte da obra reflete um acontecimento real vivenciado por ele, Charlotte e Kestner, a tragédia de Karl Wilhelm Jerusalem. Karl era parte do círculo de amigos dos três e após se apaixonar por uma mulher comprometida e de forma não 
correspondida, escolhe as vias do suicídio como solução final para sua vida. Kestner é quem conta a história para Goethe, através de cartas, lamentando que fora ele quem emprestara a pistola ao suicida semelhante à história de Werther.

$\mathrm{O}$ romance apresenta uma grande diferença de tom entre a primeira e segunda parte que vai além de duas diferentes inspirações como já mencionado acima. Na primeira, Werther parece refletir uma visão muito mais positiva do mundo e da vida, enquanto na segunda parte, desencantado, caminha pouco a pouco para uma decisão trágica. Baseado nessa divisão, Marco Aurélio Werle (2017) sugere que na primeira parte o destaque seja Werther em uma relação de sintonia com a natureza, que se mostra suplantada por sua relação com a sociedade na segunda parte. Tal apontamento nos permite pensar as preferências de Werther, como a natureza e as coisas simples da vida que o deixam feliz, em contraponto à sociedade e às relações burguesas que o sufocam.

A colocação de Werle parece muito assertiva uma vez que essa observação condiz com as cartas e com o desenvolvimento da trama. A mudança para Wahlheim propicia a Werther o contato com o campo e o desenvolvimento de novas relações sociais, as quais parecem alegrá-lo bastante. A relação com a natureza se apresenta ao leitor desde a primeira carta em 04 de maio de 1771, na qual descreve para Guilherme a sintonia de seu espírito com a natureza: "a solidão destas Campinas paradisíacas é um bálsamo para meu peito" (GOETHE, 2017: 6), questão que reflete também o isolamento do personagem que vê a 
cidade como desagradável em relação ao campo — à qual retornaremos depois.

Entretanto, na medida em que Werther estabelece contatos e desenvolve relações, inclusive a paixão pela comprometida Carlota, sua relação com o mundo se modifica, refletindo em outros personagens, na natureza e na sociedade. Ainda na primeira parte, a carta de 19 de junho de 1771, na qual descreve seu encontro com Carlota, a relação entre a natureza e sentimentos torna-se clara quando Werther escreve: "desde esse momento, sol, lua, estrelas podem seguir tranquilas a sua órbita, que para mim já não há mais dia nem noite, e o mundo inteiro dissipou-se à minha volta" (GOETHE, 2017: 43). Da mesma forma, observamos uma grande mudança de tom na segunda parte na carta de 03 de novembro de 1772: “Oh, toda essa magnífica natureza é fria para mim, inanimada como uma estampa colorida, e todo esse espetáculo já não consegue bombear do coração a cabeça a menor gota de um sentimento venturoso" (GOETHE, 2017: 122).

A ode à natureza presente no livro reflete muito do movimento alemão no qual Goethe estava inserido, Sturm und Drang, para o qual a natureza era fonte de vida, poesia e beleza. Além da sintonia dos sentimentos de Werther com a natureza, é possível compreender a importância desse contato para as expressões humanas nas mais variadas formas. Ao longo da obra tal relação é percebida, por exemplo, através da pintura na qual Werther reflete sua alma feliz, especialmente nas primeiras cartas, porque após vários desencantos com a vida ele 
parar de pintar. $\mathrm{O}$ mesmo acontece com a música e a poesia, ${ }^{3}$ visíveis especialmente nas cartas sobre Carlota, pois ambos possuíam gostos semelhantes e um espírito artístico aguçado. A valorização destas expressões aparecem em forma de crítica social em cartas como a de 20 de julho de 1771, na qual reclama que a perda do espírito artístico e das vontades pessoais é o mesmo que não viver, pois "tudo nessa vida acaba em bagatela e aquele que, para agradar aos outros se mata trabalhando por dinheiro, honras ou o que for, sem que isso o mova sua própria paixão ou necessidade, é, com certeza, um tolo" (GOETHE, 2017: 60). Ao descrever de maneira sutil em suas cartas seu ideal de vida e as coisas que dão satisfação à sua alma, Werther percebe uma incompatibilidade cada vez maior entre suas aspirações pessoais e as da sociedade burguesa.

Sua ida para Wahlheim se apresenta desde o início como um refúgio da cidade, da qual o personagem parece querer distanciamento. Ao longo da obra tais escolhas tomam contornos de crítica, especialmente na segunda parte, em particular no que se refere ao retorno de Werther para a cidade para trabalhar na corte ao lado de um embaixador. A experiência na corte se mostra frustrante, especialmente quando em uma reunião na casa do conde, Werther precisa se retirar por ser de camada social mais baixa. A situação enfrentada por ele é descrita na carta de 15 de março de 1772 com muita revolta, como no trecho a seguir:

${ }^{3}$ Destaque para o poeta grego Homero e do herói irlandês do século III d.C. Ossian que, para Marco Aurélio Werle, refletem as duas partes da obra marcadas por sensibilidades diferentes, da alegria e beleza do mundo grego ao mundo nórdico e sombrio. 
O que mais me vexa são essas fatais relações burguesas. Sei bem, como qualquer outro, que é necessária a distinção de classes e conheço as vantagens que ela traz para mim mesmo; mas não gostaria que essa mesma distinção atravancasse o meu caminho quando poderia conduzir-me a alcançar um pouco de alegria, ou fazer-me gozar um vislumbre da felicidade deste mundo(GOETHE, 2017: 91).

O relato de Werther nos permite pensar a vida de Goethe — um sujeito oriundo da burguesia que critica a aristocracia - como um reflexo real da Alemanha no século XVIII, o que nos mostra mais uma vez que a literatura pode ser uma grande chave de interpretação histórica. Ao levar em consideração os contextos de produção das obras literárias, movimentos culturais e sociais do período, ou de envolvimento do escritor, é possível realizar uma leitura mais direcionada, permitindo assim, em muitos casos, encontrar elementos reveladores dessa realidade contextual. Embora, muitas vezes não seja o objetivo do escritor falar sobre sua realidade, muitos elementos linguísticos, de mentalidade, expressão de mundo e mesmo personagens, permitem essa identificação.

É possível perceber que, quanto maior seu desencanto com a sociedade, maior sua aproximação com a natureza, e não é à toa que, diante dessa experiência, Werther encontra refúgio nas montanhas. Isto reflete de maneira bem clara o contraste entre essa pureza e autenticidade natural e o mundo burguês superficial, atrelado a regras e etiquetas sociais. Esse desencontro faz com que, no dia 24 seguinte, 
Werther peça demissão e, antes de retornar à Wahlheim, viaje até sua terra natal.

Ao retornar ao local que viveu por muito tempo na companhia de um amigo, Werther descreve sua visita, demonstrando grande saudosismo pelo passado. Na carta do dia 09 de maio de 1772, relata que a cidade passou por inúmeras mudanças e demonstra desagrado por elas, escreve "aproximei-me da cidade, saudei os jardins e as casinhas que reconhecia; as novas não me agradavam, assim como todas as alterações que haviam feito em qualquer outra parte" (GOETHE, 2017: 105). Para Löwy, esse

desejo ardente de reencontrar o lar, retornar à pátria, no sentido espiritual, e é precisamente a nostalgia que está no âmago da atitude romântica. $\mathrm{O}$ que falta no presente existia antes, em um passado mais ou menos longínquo (LÖWY; SAYRE, 2015: 44).

Ao combinar diversas críticas e apresentar determinados comportamentos em relação ao que acontece em sua vida, podemos perceber o quanto a obra de Goethe se mostra uma visão romântica pela definição teórica de Michel Löwy (LÖWY; SAYRE, 2015). De acordo com a tipologia estabelecida pelo historiador, poderíamos classificar Werther como um romântico restitucionalista, na medida em que ele corresponde às características apontadas por Löwy: demonstra saudade do passado; valoriza muito as relações sociais que faz em Wahlheim as quais não encontra na sociedade burguesa; critica muito a racionalidade empregada nesses meios e, especialmente quanto ao 
trabalho, critica sua mecanicidade que impede o desenvolvimento natural da alma.

Essa série de questões evidencia o embate entre a sociedade e o sujeito, que parece ser a problemática central do drama de Werther, uma vez que a sociedade não permite o desenvolvimento da subjetividade, pois "as regras, por mais que se diga algo em favor delas, destroem o verdadeiro sentimento da natureza e sua genuína expressão" (GOETHE, 2017: 27) - referindo-se ao amor, às artes, à poesia. Ao que parece, o contato com esse mundo do campo, não contaminado pelas regras da sociedade burguesa, permite que Werther realize e conduza sua vida através das vontades de seu coração. Na carta do dia 16 de junho de 1771, ele escreve "...o que eu ler tem de se adequar inteiramente ao meu gosto. E o autor que prefiro é sempre aquele que reflete de modo mais exato o meu mundo" (GOETHE, 2017: 36). Por que então, não pensar que ele enquanto autor preferido da juventude alemã não estaria refletindo também seu próprio contexto?

Além disso, quanto à experiência na corte, esta não só parece frustrar Werther como intensificar sua dor, o que pode possivelmente condizer com a especulação de Werle de que a sociedade racional e as relações artificiais da qual ele tenta fugir, se refletem na figura de Alberto (WERLE, 2017: 40). Através da descrição de características e diálogos das cartas, é possível compreender melhor o perfil deste homem: inteligente, responsável, de negócios, extremamente racional, com o qual Werther disputa Carlota. Mais que uma história de amor naufragada, as cartas refletem o conflito de subjetividade na qual Werther se encontra e no qual se mostra incompatível com a sociedade, 
e mais ainda quando comparado a Alberto, um representante modelo dela. Em uma das discussões de Werther com Alberto, ele contraria sua demasiada racionalidade para com algumas questões, como na carta de 12 de agosto. Nela, Werther demonstra sua revolta contra as regras e alfineta o amigo "pacato":

Mas também na vida cotidiana resulta algo intolerável ouvir todo mundo gritar, sempre que alguém pratica um ato um tantinho mais livre, honrado, inesperado: 'aquele homem está bêbado, está louco!' Tende vergonha na cara vós os pacatos! Tende vergonha na cara vós os discretos!' (GOETHE, 2017: 69).

Alberto parece representar o homem dessa sociedade modelo, de comportamento tido como ideal e racional, intensificando a incompatibilidade de Werther com esse mundo.

Sua relação com a sociedade e com alguns personagens da obra são analisados por Igor Fernandes Viana de Oliveira (2008) sob a perspectiva social, uma vez que para ele os conflitos enfrentados por Werther refletem as transformações do século XVIII acerca de uma nova sociabilidade emergente. Oliveira comenta sobre o formato da obra que permite uma aproximação maior entre escritor e leitor, o que para ele se diferencia das demais obras do século XVIII. Para ele, Os Sofrimentos do Jovem Werther:

Não objetiva retratar a sociabilidade do mundo político 'oficial' ou mesmo as relações formais estabelecidas entre nobres e famílias, mas iluminar uma sociabilidade 
'natural', quase autêntica, entre homens comuns de uma região simples” (OLIVEIRA, 2008: 11).

Essa observação parece pertinente e justificável na carta de 21 de junho de 1771 quando escreve "como me sinto feliz por ter um coração feito para sentir as alegrias simples e inocentes do homem que põe na sua mesa a cabeça de repolho que ele mesmo cultivou" (GOETHE, 2017: 45). Não à toa que os indivíduos simples, como moradores da região e crianças são os que mais despertam a atenção do personagem. Esta postura também é um diagnóstico do perfil romântico de Goethe, que sente "dolorosamente a alienação das relações humanas, a destruição das antigas formas 'orgânicas' e comunitárias da vida social" (LÖWY; SAYRE, 2015: 66).

Embora muitas cartas transmitam solidão ao leitor, como se Werther fosse um ponto fora da curva nessa sociedade, um verdadeiro desajustado, alguns desses personagens simples que surgem ao longo da obra sugerem que ele não está sozinho. Seja pelo exemplo do lavrador da carta de 30 de maio de 1771 ou pelo colhedor de flores em 30 de novembro de 1772 , representados em dois momentos diferentes da obra. Ambos são exemplos de personagens que longe do estado de racionalidade, demonstram angústias parecidas com as de Werther. O primeiro, ao descrever sua amada, leva Werther a escrever: "Que encanto ouvi-lo falar das feições dela, de seu corpo que, mesmo carecendo de atrativos juvenis, atraía-o com violência e a ela o encadeava!” (GOETHE, 2017: 31). O segundo, colhedor de flores, afirma sobre sua triste história de amor: “"...houve um tempo em que eu estava tão bem! Hoje, acabou-se tudo para mim..." e ainda sobre ser 
feliz comenta "“queria sê-lo como fui outrora!"” (GOETHE, 2017: 127).

Os personagens dos quais Werther se aproxima dão ao leitor a sensação de refletirem sua alma, especialmente quando se refere ao amor não correspondido, ao olhar social lançado sobre eles e sobre a saudade de um tempo feliz que não voltará. Além disso, assim como em várias conversas com Alberto, o contato com esses "loucos" parece sempre uma crítica a tão valorizada racionalidade do século XVIII, que tanto Werther quanto Goethe parecem recusar.

\section{Considerações finais}

Diante das questões explanadas ao longo do texto, podemos retomar alguns pontos como considerações finais e outros que não foram trabalhados, mas que auxiliam na compreensão da obra. Goethe utiliza algumas referências ao longo da obra que parecem de fundamental importância mas que são difíceis de analisar quando não conhecidos de forma profunda; como o literato Lessing, poetas como Homero, Shakespeare e Ossian e ao longo de todo texto a Bíblia - que podemos pensar como uma aproximação com vistas de se reencantar com o mundo através da religião, como propõe Löwy. Quanto a referências externas que podem ser observadas temos Herder que parece ser a principal influência de Goethe, além de ser um pensador importante em seu contexto de modo geral.

Ademais, suas ideias contrárias aos ditos valores universais encontram correspondência na ideia de Kultur em oposição a Zivilisation, conforme abordado no início, valorizando a própria cultura alemã em detrimento do que é externo a ela. Seu posicionamento crítico 
em relação ao Iluminismo, à racionalidade e ao progresso permite aproximar a crítica rousseauísta produzida pelo Sturm und Drang, que não só fez reprovações, mas propôs um novo projeto social, pautado em novos valores. Muitas passagens permitem compreender Goethe dentro deste grupo e pensá-lo como um autor romântico, seja pela crítica ao presente e saudade de um passado que não retornará, seja pelo pessimismo quanto ao futuro e às novas relações humanas e de trabalho, conforme destaca Michel Löwy (LÖWY; SAYRE, 2015).

Alguns desses elementos nos levam a analisar Os Sofrimentos do Jovem Werther (1774) para além de um romance não correspondido que resulta em suicídio, pois ao dispor de uma base histórica sobre o período, é possível compreender que a frustração maior de Werther é em relação à sociedade que está se modificando. $\mathrm{O}$ problema amoroso acaba por intensificar sua angústia e sua sensação de incompatibilidade entre o indivíduo e a sociedade. As transformações sociais observadas por Werther negligenciam elementos de fundamental importância para ele como o autodesenvolvimento, fazendo com que a felicidade se mostre cada vez mais distante e seu único consolo seja a natureza. Além disso, o pessimismo de Werther em certa medida reflete o do próprio Goethe e, se pensarmos no sucesso da obra, da sociedade alemã que se vestiu conforme o vestuário do personagem descrito por Goethe e chegou mesmo a se suicidar conforme Werther. Isto tudo, sem dúvida, nos faz repensar conceitos monoparadigmáticos (ROSSI, 2000) como a ideia de progresso, associada em geral à ideia de melhora e avanço, mas que possui um significado bastante relativo dependendo do interlocutor. Neste caso, Goethe, através de Werther, encara a dita história moderna 
com receios e críticas. E, ao analisar esta crítica construída através da estrutura literária, podemos realizar uma interpretação da História, na medida em que alguns elementos permitem aproximações ou distanciamentos com movimentos reais do passado.

\section{Bibliografia}

GOETHE, Johann Wolfgang von. Os sofrimentos do jovem Werther. Porto Alegre: L\&PM, 2017. Edição crítica, tradução, prefácio, organização e notas de rodapé de Marcelo Backes.

LÖWY, Michel; SAYRE, Robert. O que é o romantismo? Uma tentativa de redefinição; Esboço de uma tipologia. In: Revolta e melancolia. São Paulo: Boitempo, p. 19-112, 2015.

MOREIRA, Márcio Macedo. Cultura Pré-Romântica: crítica ao Iluminismo e idéia de Decadência (1750-1784). In: XIII Encontro Estadual de História/ História e Historiografia: Entre o nacional e o regional, 2008, Guarabira-PB. Anais eletrônicos, 2008. Disponível em: $<\mathrm{http}$ //www.anpuhpb.org/anais_xiii_eeph/textos/ST\%2010\%20-\%20M $\% \mathrm{C} 3 \% \mathrm{~A} 1 \mathrm{rcio} \% 20 \mathrm{Mac} \% \mathrm{C} 3 \% \mathrm{AA}$ Ado $\% 20 \mathrm{Moreira} \% 20 \mathrm{TC} . \mathrm{PDF}>$. Acesso em: 24 jun. 2018.

OLIVEIRA, Igor Fernandes Viana de. Essas "odiosas distinções sociais": Os sofrimentos do jovem Werther e as transformações no espaço público - Século XVIII. In: Revista eletrônica cadernos de história: Universidade Federal de Ouro Preto, Mariana, ano III, v. VI, n.2, p.6-15, dez 2008. Disponível em: $<$ https://slidex.tips/download/palavras-chave-goethe-seculo-xviii-espaopublico $>$. Acesso em: 26 jun. 2018.

ROSSI, Paolo. De progresso verum cogitata et visa. In: Naufrágios sem espectador - A ideia de progresso. São Paulo: Unesp, 2000, p. 111-144.

SILVA, Felipe Vale da. Subjetividade e experiência em Die Leiden des jungen Werthers e Wilhelm Meisters theatralische Sendung de J. W. 
Goethe. 2012. Dissertação (Mestrado em Língua e Literatura Alemã) Faculdade de Filosofia, Letras e Ciências Humanas, Universidade de São Paulo, São Paulo, 2012. Disponível em: $<$ http://www.teses.usp.br/teses/disponiveis/8/8144/tde-06122012-14563 2/pt-br.php>. Acesso em: 25 jun. 2018.

WERLE, Marco Aurélio. Natureza e sociedade no Werther de Goethe. In: Revista Eletrônica Artefilosofia, n. 22, jul. 2017, p. 39-49. Disponível em: $<$ http://www.periodicos.ufop.br/pp/index.php/raf/article/view/840/795>. Acesso em: 24 jun. 2018.

Recebido em: 19/08/2019 Aceito em: 04/06/2020 